\title{
Angstrom-Prescott Model for Predicting Global Solar Radiation in Mubi, Nigeria
}

\begin{abstract}
Ogbaka D. $T^{1}$, Benjamin, A. $H^{2}$ \& Jummai, V. $z^{3}$

${ }^{1}$ Dept. of Pure and Applied Physics, Faculty of Science, Adamawa State University, Mubi, Adamawa State, Nigeria.

${ }^{2}$ Dept. of Physics, Faculty of Science, Adamawa State College of Education, Hong, Adamawa State, Nigeria.

${ }^{3}$ Dept. of Geography, Adamawa State University, Mubi, Adamawa State, Nigeria.
\end{abstract}

\section{Corresponding Author}

Ogbaka D.T

DOI: $10.38177 / A J B S R .2020 .2209$
Abstract: Researchers In this study Angstrom-Prescott model was used to estimate the global solar radiation based on the monthly mean sunshine hour for Mubi town, Adamawa State. Several models have been proposed to estimate global solar radiation. The Angstrom constants $a$ and $b$ of Angstrom-type correlation used in estimating monthly average global solar radiation was estimated to be 0.27 and 0.54 respectively. The model developed has a good correlation coefficient with $r=$ 0.87 , obtained for this analysis shows the model best fits the data. The Angstrom-Prescott model developed in this study can also be applied to other cities to predict global solar radiation. The global solar radiation intensity predicted in this study can also be utilized in design, analysis and performance estimation of solar energy systems, which is gaining significant attention in Nigeria and the world at large.

Keywords: Global Solar Radiation, Sunshine Duration, Angstrom-Prescott, Models, Relationship.

\subsection{Introduction}

Solar energy technologies offer a clean, renewable and domestic energy source and are essential components of a sustainable energy future. The amount of global solar radiation and its temporal distribution are the primary variable for the use of solar energy [1]. Development of a solar energy research program must always start with a study of solar radiation data at a site or region of interest [2]. Unfortunately, the measurement of these parameters is made only in a few meteorological stations, especially in developing countries, for both historical and economic reasons. For places where it is not directly measured, solar radiation can be estimated by using models and empirical correlations. Therefore, there have been numerous investigations on the examination of the relationship between global radiation and sunshine duration for which data are available in a greater number of meteorological stations [3].

Solar energy is the most important energy resource to man and indeed it is essential factor for human life. Solar energy is the clean, abundant, renewable and sustainable energy resource from the sun which reaches the earth in form of light and heat. Solar energy occupies one of the most important places among the various possible alternative energy sources for both urban and rural areas. An accurate knowledge of the solar radiation 
distribution at a particular geographical location is of vital importance for the development of many solar energy devices and for estimates of their performance [4].

This aggressive consumption rate of fossil fuels has created unacceptable environmental problems such as greenhouse effects, which may lead to disastrous climatic consequences. Thus, renewable and clean energy such as that obtained by using solar cells is required to maintain the quality of human life as well as the environment [5].

Several models have been proposed to estimate global solar radiation. Authors in [6] presents a linear regression model used in correlating the global solar radiation data with relative sunshine duration, which is a modified Angstrom type model [4]. Authors in [7] studied the correlation between the measurements of global solar radiation and the meteorological parameters using solar radiation, mean daily maximum temperature, mean daily relative humidity, mean daily sea level pressure, mean daily vapour pressure, and hours of bright sunshine data obtained from different parts of Egypt. Authors in [8] have demonstrated the predictive ability of the Angstrom type model, correlating the global solar radiation to relative sunshine duration in a simple linear regression form.

Authors in [9] observed that the meteorological stations measuring solar radiation data in the developing countries are few. This situation can be solved by using empirical models, which estimate global solar radiation based on the relationships with frequently measured climatic variables. Solar energy occupies one of the most important places among the various possible alternative energy sources. An accurate knowledge of solar radiation distribution at a particular geographical location is of vital importance for the development of many solar energy devices. Unfortunately, for many developing countries solar radiation measurements are not easily available due to the shortage of measurement equipment's [10]. This paper therefore presents and validates a new model of the Angstrom-Prescott type for the estimation of monthly average daily global solar radiation in Mubi, Nigeria.

\subsection{Materials and Method}

The monthly mean daily data for sunshine hours were obtained from Department of Geography metrological unit situated in Adamawa State University, Mubi. The data obtained covered a period of five years (2009 - 2013) for Mubi, Nigeria located on latitude 10.26670 $\mathrm{N}$ and longitude $13.2667^{\circ} \mathrm{E}$.

Various climatic parameters have been used in developing empirical relations for predicting the monthly average global solar radiation. Among the existing correlations, the following relation is the generally accepted modified form of the Angstrom-type regression equation, relating the monthly average daily global radiation to the average daily sunshine hours [7]. 
$\frac{H_{m}}{\bar{H}_{o}}=a+b \frac{S}{S_{0}}$

Where $H_{m}$ is the monthly average global solar radiation $\left(\mathrm{MJm}^{-2} \mathrm{day}^{-1}\right), S$ is the monthly average daily bright sunshine hour, $S_{0}$ is the maximum possible monthly average daily sunshine hour or the day length, $a$ and $b$ are coefficients of Angstrom's formula.

$H_{o}$ is the monthly average daily extraterrestrial radiation which can be expressed as:

$H_{O}=\frac{24}{\pi} I_{S C}\left[1+0.033 \cos \frac{360 n}{365}\right]\left[\cos \emptyset \cos \delta \sin \omega_{s}+\frac{\pi}{180} \omega_{s} \sin \emptyset \sin \delta\right]$

Where $n$ is the Julian day number, $I_{s c}=1367 \mathrm{Wm}^{-2}$ is the solar constant, $\emptyset$ is the latitude of the location, $\delta$ is the declination angle [11] given as:

$\delta=23.45 \sin \left(360 \frac{284+n}{365}\right)$

And $\omega$ is the sunset hour angle as:

$\omega=\cos ^{-1}(-\tan \emptyset \tan \delta)$

The maximum possible sunshine duration $\bar{S}_{0}$ is given by:

$S_{0}=\left(\frac{2}{15}\right) \omega$

According to [12], regression coefficient $a$ and $b$ from the calculated monthly average global solar radiation has been obtained from the relationship given as:

$\mathrm{a}=-0.110+0.235 \cos \emptyset+0.323\left(\frac{S}{s_{0}}\right)$

$\mathrm{b}=1.449-0.553 \cos \emptyset-0.694\left(\frac{s}{s_{0}}\right)$

compute estimated values of the monthly average daily global radiation $H_{m}$, the values of computed $a$ and $b$ from equations (6) and (7) were used in Equation (1).

The correlation coefficients $r$ between estimated and measured radiation values was defined by [13]:

$r=\frac{\sum\left(\bar{H}_{\text {estimated }}-\bar{H}_{e}\right)\left(\bar{H}_{\text {measured }}-\bar{H}_{m}\right)}{\sqrt{\left(\sum\left(\bar{H}_{\text {estimated }}-\bar{H}_{e}\right)^{2}\right)\left(\sum\left(\bar{H}_{\text {measured }}-\bar{H}_{m}\right)^{2}\right)}}$

\subsection{Results AND DISCUSSION}

Table 1: Metrological data and Global Solar Radiation for Mubi

\begin{tabular}{|c|c|c|c|c|c|c|c|}
\hline Month & $\overline{\bar{S}}$ (hr) & $\bar{S}_{\mathrm{o}}(\mathbf{h r})$ & $\overline{\bar{S}} / \bar{S}_{\mathrm{o}}$ & $\boldsymbol{H}_{m}$ & $\boldsymbol{H}_{\boldsymbol{o}}$ & $\frac{\boldsymbol{H}_{m}}{H_{o}}$ & $\frac{H_{e}}{H_{o}}$ \\
\hline Jan & 6.26 & 12.55 & 0.58 & 21.42 & 39.41 & 0.54 & 0.53 \\
\hline
\end{tabular}




\begin{tabular}{llllllll}
\hline Feb & 5.92 & 7.01 & 0.84 & 22.32 & 27.95 & 0.79 & 0.76 \\
\hline Mar & 7.61 & 13.56 & 0.64 & 23.89 & 39.70 & 0.60 & 0.65 \\
\hline Apr & 5.48 & 12.54 & 0.53 & 22.39 & 33.67 & 0.66 & 0.56 \\
\hline May & 6.18 & 12.55 & 0.57 & 21.20 & 39.28 & 0.53 & 0.59 \\
\hline Jun & 5.42 & 12.54 & 0.43 & 19.62 & 33.87 & 0.57 & 0.47 \\
\hline Jul & 5.12 & 12.55 & 0.42 & 19.05 & 39.14 & 0.48 & 0.47 \\
\hline Aug & 5.22 & 12.55 & 0.40 & 17.67 & 37.71 & 0.46 & 0.45 \\
\hline Sep & 5.62 & 12.54 & 0.45 & 18.67 & 33.81 & 0.55 & 0.52 \\
\hline Oct & 5.81 & 12.55 & 0.46 & 19.39 & 39.54 & 0.49 & 0.52 \\
\hline Nov & 5.75 & 12.54 & 0.45 & 19.47 & 33.76 & 0.57 & 0.54 \\
\hline Dec & 4.97 & 12.55 & 0.48 & 19.60 & 39.34 & 0.49 & 0.48 \\
\hline
\end{tabular}

Table 2: Monthly mean average of regression constants, extraterrestrial solar radiation, measured and calculated values, measured and calculated clearness index for Mubi.

\begin{tabular}{lccccc}
\hline Month & $\mathbf{A}$ & $\mathbf{b}$ & $\mathbf{H}_{\mathbf{m}}$ & $\mathbf{H}_{\mathbf{o}}$ & $\mathbf{H}_{\mathbf{e}}$ \\
\hline Jan & 0.27 & 0.54 & 21.42 & 39.41 & 21.06 \\
Feb & 0.40 & 0.43 & 22.32 & 27.95 & 21.27 \\
Mar & 0.30 & 0.56 & 23.89 & 39.70 & 26.13 \\
Apr & 0.25 & 0.60 & 22.39 & 33.67 & 19.12 \\
May & 0.28 & 0.55 & 21.20 & 39.28 & 23.31 \\
\hline Jun & 0.25 & 0.53 & 19.62 & 33.87 & 16.18 \\
\hline Jul & 0.25 & 0.54 & 19.05 & 39.14 & 18.66 \\
\hline Aug & 0.25 & 0.52 & 17.67 & 37.71 & 17.27 \\
\hline Sep & 0.26 & 0.52 & 18.67 & 33.81 & 17.60 \\
\hline & & & & & \\
\hline
\end{tabular}




\begin{tabular}{llllll}
\hline Oct & 0.27 & 0.55 & 19.39 & 39.54 & 20.67
\end{tabular}

$\begin{array}{llllll}\text { Nov } & 0.27 & 0.56 & 19.47 & 33.76 & 18.52 \\ \text { Dec } & 0.23 & 0.53 & 19.60 & 39.34 & 19.05\end{array}$

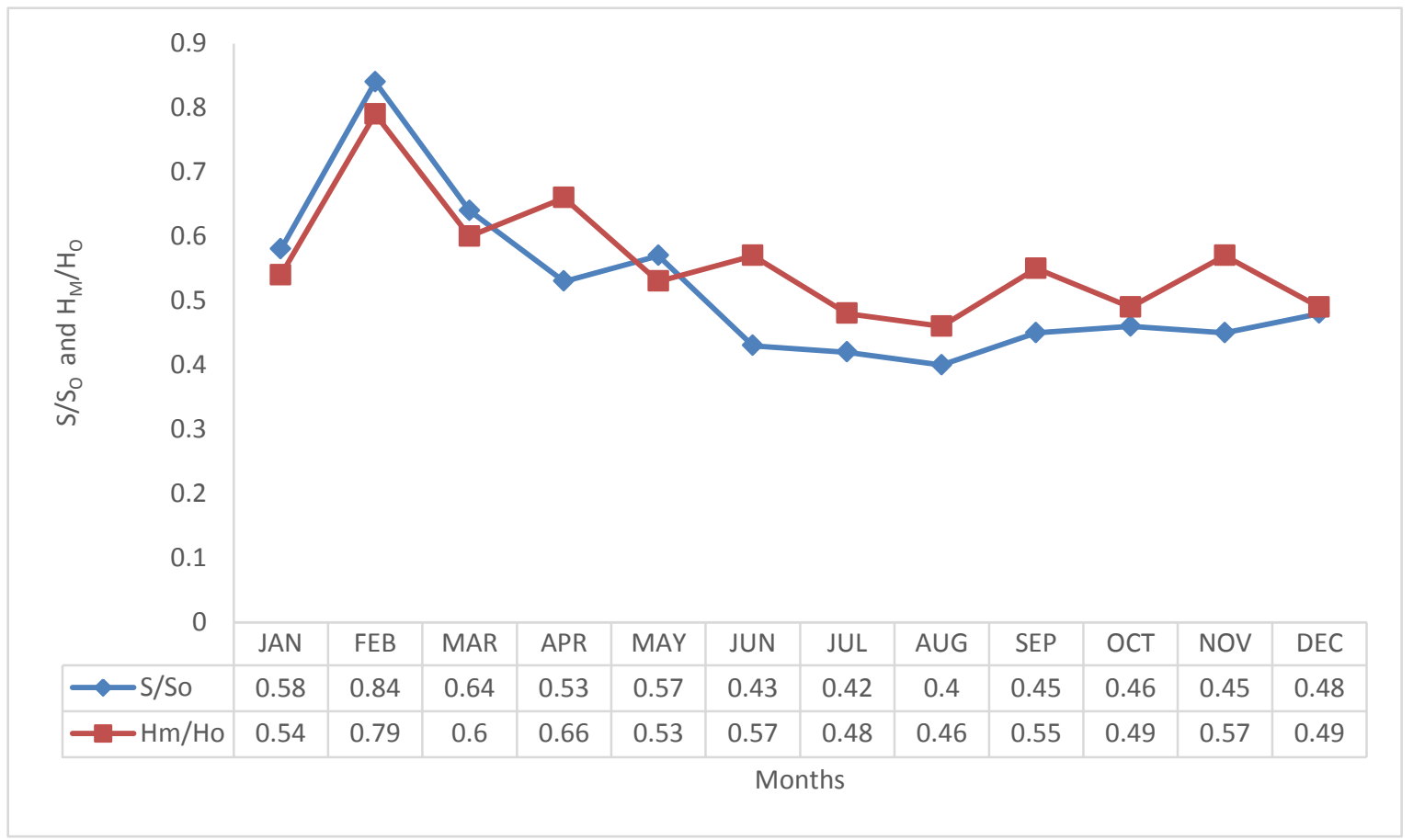

Fig. 1: Variation of $S / S_{o}$ and $H_{m} / H_{o}$ (The clearness index) for Mubi

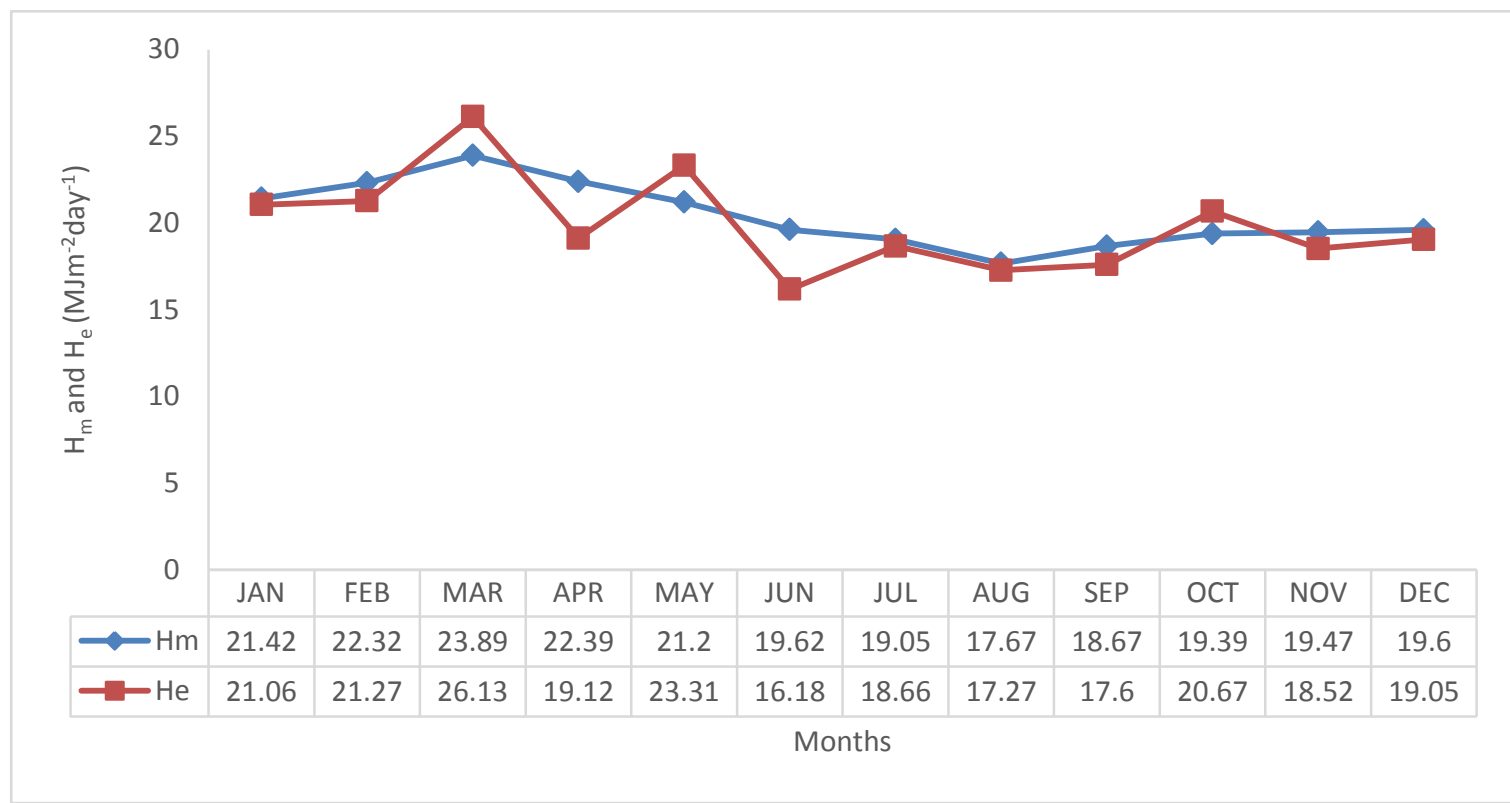

Fig. 2: Comparison between measured and predicted Solar Radiation

The extraterrestrial solar radiation $\mathrm{H}_{\mathrm{o}}\left(\mathrm{MJm}^{-2}\right.$ day $\left.^{-1}\right)$ and the monthly day length $\mathrm{S}_{\mathrm{o}}(\mathrm{hr})$ were computed for each month using equations (2) - (5), the input parameters for the calculation 
of the mean monthly global solar radiation for Mubi are shown in the Table 1 and 2 . Using these parameters, the regression constants ' $a$ ' and ' $b$ ' evaluated as 0.27 and 0.54 respectively. Substituting these values into equation (1), we now established the empirical correlation for the estimation developed for Mubi as:

$\frac{H_{m}}{H_{o}}=0.27+0.54\left(\frac{S}{S_{o}}\right)$

The model developed has a good correlation coefficient with $r=0.87$, the coefficient of determination, $\mathrm{R}^{2}$, (70.68\%) obtained for this analysis shows the model best fits the data. The value of $\mathrm{H}_{\mathrm{e}} / \mathrm{H}_{\mathrm{o}}(=0.45)$ corresponding to the lowest value of $S / S_{0}(=0.40)$ and $\mathrm{H}_{\mathrm{e}}$ $\left(17.27 \mathrm{MJm}^{-2} \mathrm{day}^{-1}\right)$ in the month of August is an indication of poor sky condition. These conditions correspond to the general wet or rainy season (June - September) observed in Nigeria, during which there is much cloud cover.

The regression constants (Table 3), a and b of different months were evaluated from equations (7) - (8). To compute the calculated values of the mean monthly average of global solar radiation $\mathrm{H}_{\mathrm{e}}$, the values of $\mathrm{a}$ and $\mathrm{b}$ were inserted into equation (1) and the correlation may be used to compute $\mathrm{H}_{\mathrm{e}}$ at other locations having the same altitude. Looking at these values of measured and calculated clearness indexes; it is observed that both of them had the lowest values in the month of August. (Throughout the year) $H_{m} / H_{\circ}(=0.46), H_{e} / H_{\circ}(=$ $0.45)$ with $\mathrm{H}_{\mathrm{m}}\left(17.67 \mathrm{MJm}^{-2} \mathrm{day}^{-1}\right)$ and $\mathrm{H}_{\mathrm{e}}\left(=17.27 \mathrm{MJm}^{-2}\right.$ day $\left.^{-1}\right)$ which can be traced to the meteorological conditions for Mubi.

The value of the clearness index and the relative sunshine duration in Table 2 were observed to be 0.45 and 0.40 respectively. The results suggest that the rainfall in Kebbi is at peak during the month of July - August when the sky is cloudy and the solar radiation is fairly low. However, just immediately after the August minimum, the clearness index and the relative sunshine duration increased remarkably with the cloud cover crossing over the clearness index. Both the values of the clearness index and relative sunshine duration in November reached peaks at 0.45 and 0.46 respectively. This implies that a clear sky will obviously fell within the dry season and hence a high solar radiation is experienced. Obviously, this is generally dry season period in Nigeria. This provides favorable condition for solar energy.

\section{4..0 Conclusion}

In line with world concern about the economic importance of global solar radiation as an alternative renewable energy, the models for estimating monthly global solar radiation of Mubi, Nigeria have been developed to be: $\frac{H_{m}}{H_{o}}=0.27+0.54\left(\frac{S}{S_{o}}\right)$. The estimated global solar radiation data and its correlation will provide a useful source of information to designers of 
renewable energy, air conditioning systems and other solar energy related systems. The Angstrom-Prescott model developed in this study can also be applied to other cities to predict global solar radiation. The global solar radiation intensity predicted in this study can also be utilized in design, analysis and performance estimation of solar energy systems, which is gaining significant attention in Nigeria and the world at large.

\section{References}

[1] Gopinathan K.K. (1988). A general formula for computing the coefficients of the correlations connecting global solar radiation to sunshine duration. Solar Energy, 41, 499-502.

[2] Bakirci K., (2009). "Correlations for Estimation of Daily Global Solar Radiation with Hours of Bright Sunshine in Turkey," Energy, Vol. 34, No. 4, pp. 485-501.

[3] Solar Radiation Handbook, Solar Energy Centre, MNRE, 2008.

[4] Page, J. K., (1964), The estimation of monthly mean valuesof daily total short - wave radiation on vertical and inclined surfaces from sunshine records. Proceeding of the UN Conference on New Sources of Energy, Pp. 98.

[5] Mandalia H. C., Jain V. K. and Pattanaik B. N., (2012), Application of Super-molecules in solar energy conversion, A Review, Res. J. Chem. Sci., 2(1), 89-102.

[6] Babatunde E.B, Aro T.O (1990). Characteristics Variation of total solar radiation at Ilorin, Nigeria. Nig. J. Sol. Energy 9: 157 - 173.

[7] Angstrom, A., (1924), Solar and Terrestrial Radiation, J. Meteor. Soc., 50: 121-126.

[8] Trabea, A.A. and M.A. Shaltout, 2000. Correlation of global solar-radiation with meteorological parameters over Egypt. Renew. Energ., 21: 297-308.

[9] Falayi, E. O. and A. B. Rabiu, (2005), Modelling global solar radiation using sunshine duration data. Nigeria Journal of Physics, Vol. 17, pp. 181-186.

[10] Okundamiya M.S. and Nzeako A.N., (2010). Empirical Model for Estimating Global Solar Radiation on Horizontal Surfaces for Selected Cities in the Six Geopolitical Zones in Nigeria. Research Journal of Applied Sciences, Engineering and Technology. 2(8): 805-812. [11] Cooper, P.I., (1969). The absorption of solar radiation in solar stills. Solar Energ., 12(3): 333-346.

[12] Tiwari, G.N. and Sangeeta S. (1997). Solar Thermal Engineering System, Narosa Publishing House, New Dehli, India.

[13] Nguyen B.T. and Pryor, T. L. (1997), The relationship between global solar radiation and sunshine duration in Vietnam. Renewable Energy, II. 47(60). 